\title{
Sensorineural deafness with dilated cardiomyopathy
}

INSERM

\section{Source}

INSERM. (1999). Orphanet: an online rare disease and orphan drug data base.

Sensorineural deafness with dilated cardiomyopathy. ORPHA:217622

Sensorineural deafness with dilated cardiomyopathy is an extremely rare autosomal dominant syndrome described in two families to date and characterized by moderate to severe sensorineural hearing loss manifesting during childhood, and associated with lateonset dilated cardiomyopathy that generally progresses to heart failure. 